\title{
A VARIANT OF CHEBYSHEV INEQUALITY WITH APPLICATIONS
}

\section{ZHENG LIU}

Abstract. A varaint of Chebyshev inequality is established and it is applied to obtain some inequalities for expectation, variance and cumulative distribution functions as well as to provide new proofs for some classical inequalities.

Mathematics subject classification (2010): 26D15.

Keywords and phrases: Chebyshev inequality, expectation, variance, cumulative distribution function, trapezoid inequality, midpoint inequality, Simpson inequality.

\section{REFERENCES}

[1] D. S. Mitrinović, J. E. PeČarić And A. M. Fink, Classical and New Inequalities in Analysis, Kluwer Acad. Publ., Dordrecht/Boston/Lancaster/Tokyo, 1993.

[2] M. Matić, J. E. PeČARić And N. Ujevic, On new estimation of the remainder in generalized Taylor's formula, Math. Ineq. \& Appl., 3, 2 (1999), 343-361.

[3] N. S. BARNETT AND S. S. DRAGOMIR, Some inequalities for random variables whose probability density functions are absolutely continuous using a pre-Chebychev inequality, Tamkang J. of Math. 32, 1 (2001), 55-60.

[4] N. S. BARNETT AND S. S. DRAGOMIR, An inequality of Ostrowski's type for cumulative distribution functions, Kyungpook Math. J. 39, 2 (1999), 303-311.

[5] N. S. Barnett, S. S. Dragomir And R. P. Agarwal, Some inequalities for probability, expectation and variance of random variable defined over a finite interval, Comput. Math. Appl., 43 (2002), 1319-1357. 